\title{
The Impact of Aging on Fertility: Similarities and Differences between Ovaries and Testes
}

\author{
Alice Ioana Albu and Dragos Albu \\ Additional information is available at the end of the chapter \\ http://dx.doi.org/10.5772/intechopen.68905
}

\begin{abstract}
The increasing age seems to have a negative impact on reproductive functions not only in women but also in men. Therefore, our aim was to review the data available in the literature regarding the impact of advancing age on fertility and the mechanisms underlying this association in both genders. The available data suggest that the effects of age on ovarian function cause a decrease in fertility starting 13 years before menopause. Statistics show that $10 \%$ of women will have a decreased fertility starting with the age of 30 . The impact of age on ovary is due to both decreased number and quality of the oocytes, resulting in a high rate of chromosomal aneuploidy in the embryo and mitochondria dysfunction. Assisted reproductive technologies aiming to identify competent embryo were created but for the moment the results are unsatisfactory. On the other hand, in men, the semen quality and testicular function were found to gradually decrease with age and most of the studies also describe a negative impact on fertility. The mechanisms underlying decreased fertility are mainly genetic and epigenetics changes. However, if the effects of age on male fertility in men can be overcome by assisted reproductive technologies is not clear yet as the results of the studies are inconsistent.
\end{abstract}

Keywords: aging, male fertility, female fertility

\section{Introduction}

The increasing age has a negative effect on reproductive function not only in women but also in men. This aspect seems to gain importance since in the last decades; there is a trend to an increased age in both genders at the first pregnancy. While the decreasing reproductive potential of women with age is well known, the modification of the reproductive function in men with increasing age is not entirely understood. The lack of a clear definition of an 
advanced reproductive paternal age and the mechanisms involved interfere with adequate counselling of the couple regarding future fertility. Therefore, our aim was to review the data available in the literature regarding the impact of advancing age on fertility and the mechanisms underlying this association in both genders.

\subsection{Methods}

We performed a review of the available data regarding the impact of advanced age on fertility in both men and women. We searched in PubMed and Google Scholar using the following key words: maternal age, paternal age, ovarian aging, fertility, infertility, chromosome aberrations, reproduction, pregnancy, pregnancy complications, assisted reproduction, ovary, and testes. Only articles written in English and French were selected.

\section{Aging and fertility in men}

\subsection{Trend of increasing paternal age}

A study published in 2006 showed an increase in paternal age over 2 decades among British couples from 29.2 years in 1980 to 32.1 years in 2002 [1, 2]. Moreover, the proportion of fathers aged 35-54 years increased from 25 in 1993 to 40\% over 10 years [1]. These data probably parallel a worldwide change in reproductive dynamic, reflecting societal changes: couples start their families later waiting for a more favorable socio-economic environment and taking into account the change in women's role in society and increased access to reproductive technologies. However, the exact impact on fertility and health of the offspring because of this increase in paternal age is not completely understood, although some studies suggest detrimental effects.

Although the effect of delaying time of conception in women is extensively studied and strategies to counteract the negative consequences on the fetus are available, the potential effect of increasing age on male fertility has just started to be evaluated. While early studies failed to find an association between higher paternal age and infertility [3, 4], recent studies suggest a detrimental effect of increasing age on a chance to conceive. In one study published in 2000, couples with pregnancies of at least 24 weeks of gestation had a decreased chance of pregnancy within 12 months in comparison with men younger than 25 years (or 0.62 for men who are 30-34 years old, 0.5 for men who are 35-39 years old, and 0.51 for men $\geq 40$ years old) [5]. Moreover, the increased paternal age seems to interact with the maternal age as suggested by the study of de La Rochbrochard and Thonneau which showed that men older than 40 years had an increased risk of infertility in couples with women older than 35 years [6]. Similarly, the study of Hassan and Killick confirmed that men older than 45 years associate with a decreased chance to achieve pregnancy within 1 year, in comparison to men younger than 25 years. [7].

The decline in male fertility with advancing age could be explained by several mechanisms. First of all, sexual dysfunction is one of the possible contributors as the frequency of the sexual intercourse significantly decreases with age and can significantly impact the fertility $[8,9]$. Furthermore, semen parameters and testosterone levels can be altered with advancing age and an increased number of genetic abnormalities could appear. 
The decline in testosterone levels as men age has been consistently reported in cross-sectional $[10,11]$ and longitudinal studies [12-17]. However, the clinical significance of this decline and the utility of testosterone administration are not completely clarified. Whether this process is part of the physiological aging or is influenced by other factors (potentially correctable) is also a subject of research. A longitudinal study published in 2013 comprising 2736 community-dwelling men aged 40-79 years [18] demonstrated that the age-related changes in testosterone levels could be influenced by lifestyle modifications: weight loss was associated with a proportional increase and weight gain with a proportional decrease in testosterone, free testosterone, and sex hormone-binding globulin (SHBG). Moreover, smoking cessation was related to a greater decline in testosterone in comparison to smokers. The number of comorbid conditions or physical activities did not seem to have an influence on hypothalamicpituitary-testicular (HPT) axis function [18]. However, this study, in agreement with the previous studies, confirmed the modest decline of testosterone and free testosterone with age, while SHBG and luteinizing hormone (LH) increased, although the mean values of hormones remain within normal ranges.

Although the testosterone level decreases with age, only a small proportion of aging men present with testosterone levels below the normal range are being diagnosed with late onset hypogonadism. Among subjects included in the European Male Aging Study (EMAS), the prevalence of late onset hypogonadism was of 2.1 among men over 40 years old and $5.1 \%$ among men over 70 years old [19].

This decrease in testosterone levels seems to be the consequence of a decline in testicular and hypothalamic function with age. Histopathological postmortem studies support this hypothesis showing a reduced number of Leydig cells ( 44\% lower in men aged 50-76 than in men aged 20-48) [20]. It was also demonstrated that the Leydig cells responsiveness to LH administration is decreased in older men [21]. An exaggerated response of gonadotropin-releasing hormone $(\mathrm{GnRH})$ to the negative feedback of testosterone and estrogen was also suggested to be involved in hypogonadism of older men [22].

However, the decrease in testosterone levels in aging men is not universally found, being probably influenced by numerous factors. A study published in 2010 demonstrated an association between polymorphisms in genes related to the pituitary-testicular endocrine function and circulating LH, testosterone, and estradiol levels [23].

Whether this decrease in testicular function has an impact on spermatogenesis is an interesting aspect which needs further clarification, taking into account the close correlation between gonadal steroids and spermatogenic functions in men.

The reports about changes of semen parameters with increasing age started in 1970 and many studies were published until today. Most of these studies found a decrease of semen volume, percentage of motile spermatozoa, and of normal morphology [24-26]. In turn, sperm concentration was reported to be unchanged [27], decreased [26], and even increased with advancing age [28] in healthy men. On the other hand, studies on infertile men demonstrated an unaltered [29] or an increase in sperm concentration [28]. However, most of these studies included a limited number of older subjects, making difficult to analyze the impact of aging on semen parameters. The study by Brahem et al. [30] demonstrated an effect of age of decreasing semen 
volume and vitality only in infertile patients in comparison with men with proven fertility. In contrast, the sperm concentration significantly increased with age [30]. The alteration of sperm parameters with age could be due to age-related histological changes observed in the testis. For instance, a study of the testes of 26 postmortem male subjects aged $16-80$ years found a significant decline in the number of Sertoli cells with age [31]. Another histological study showed that subjects over 50 years old have a decreased number of Sertoli cells and failure of spermatogenic cell development evident from the spermatid level. However, an increased apoptosis index and a decreased proliferation index were observed only in men over 70 years [32].

The age-related decline in semen parameters could be also determined by the deterioration of the function of the seminal vesicle (contributing to ejaculate volume), prostate, and epididymis [33].

\subsection{The genetic modifications during aging}

\subsubsection{DNA fragmentation}

The results of a meta-analysis, including 26 studies and 10,220 patients, showed an increased DNA fragmentation paralleling advancing age [34]. The study by Moskovtsev et al. [35] evaluated infertile men, showing that the DNA fragmentation index increased gradually from 15.2 in men $<30$ years to $19.4,20.1,26.4$, and $32.0 \%$ in men in the age groups $30-35,35-40$, $40-45$, and over 45 years [35]. The association between DNA fragmentation and increasing age was also found in men with normozoospermia and oligoasthenoteratozoospermia [36].

Sperm DNA fragmentation seems to be an important determinant of fertility since it was reported to be associated with a reduced chance to conceive, a higher time of conception [37-39], and poorer outcomes in intrauterine insemination and IVF (in vitro fertilisation)/ ICSI (intracytoplasmic sperm injection) [40-44]. Moreover, it is possible that altered sperm DNA integrity has an impact on early embryonic development according to studies reporting a reduction of embryo morphokinetic parameters [45, 46], a reduced implantation rate, [47] and a poor embryo's post-implantation development resulting in pregnancy loss [48]. The study of Sivanarayana et al. [49] showed that sperms with abnormal forms (elongated, thin, round, pyri, amorphous, micro-, and macro-forms) and abnormal motility parameters were significantly associated with a higher DNA fragmentation index [49]. Therefore, the selection of morphologically normal spermatozoa for ICSI procedure could provide a possible explanation for the divergent results of studies evaluating the association of DNA fragmentation and ICSI outcome.

\subsubsection{Aneuploidies}

Chromosomal aberrations are frequently found in human gametes (21\% of oocytes and $9 \%$ of spermatozoa) [50], with a predominance of aneuploidies in oocytes, whereas structural chromosomal abnormalities predominate in spermatozoa. Chromosomes 21, 22, and 16 are usually overrepresented in aneuploid gametes. In turn, sex chromosomes are particularly prone to non-disjunction in human sperm. Whereas the frequency of aneuploidy seems to be increased in infertile male sperm [33], the advanced paternal age is not convincingly associated with the presence of aneuploid sperms [50, 51]. Except an increased 
risk for trisomy 21 , there are contradictory evidences for trisomy $18,13,47 \mathrm{XXY}$, and $45 \mathrm{X}$ [52] associated with paternal age. Bosch et al. [53] also reported a positive linear association of age with the structural and numerical abnormalities of chromosome 9 in sperm of the healthy donors, but these findings are limited by the reduced number of subjects $(n=18)$ [53]. A study published in 2011 reviewed the data on the association between paternal age and the presence of aneuploidy in sperms and concluded that in spite of decades of research and "innumerable microscope hours", the literature is inconclusive [54]. The authors suggested that a low efficacy of FISH (fluorescence in situ hybridization) in detecting aneuploidies can be involved in the results of the studies and proposed that the array-based approaches will be a better method in addressing the question of a paternal age effect [54]. However, other methodological problems of the previous papers can be also involved as the number of patients was quite small in most of the studies and the age range was not always wide enough to be able to detect an association. A study published in 2005, evaluating testicular samples of subjects aged 29-102 years, reported that spermatogenesis is not invariably affected by age and the frequency of aneuploidies is increased only in older individuals with arrested spermatogenesis, suggesting an interaction between these two conditions [55]. An experimental study on mice also observed an association of increased age not only with sex chromosomal disomy and a high rate of germ cell apoptosis but also a high inter-individual variability in germ cell apoptosis. The authors concluded that the compromised apoptosis could contribute to high aneuploidies rate observed in older mice [56].

The study by De Souza et al. [57] showed that older fathers have an increased risk of having children with Klinefelter syndrome and XYY syndrome [57], in accordance with the described paternal origin of these sex chromosomes. Although slightly, the risk of Patau and Edwards syndromes was also increased. Arnedo et al. reported that the paternal age was associated with a higher frequency of sperm XY disomy only in fathers with paternally inherited Klinefelter syndrome offspring [58].

Trisomy 21 is the most common trisomy in newborns, and it is clearly related to increased maternal age. Surprisingly, the risk for Down syndrome seems to be negatively related to paternal age according to a study reporting a double risk for Down syndrome in all maternal age groups for younger fathers [59]. On the other hand, another study showed that paternal age is positively associated with a high risk for Down syndrome only when mothers are older than 35 [60]. However, the overall paternal contribution to Down syndrome appearance seems to be low as only in $5-10 \%$ of cases, excess 21 chromosome is of paternal origin [61].

Older studies reported no relationship between paternal age and autosomal trisomies [62, 63] or even a decreased risk of trisomy 13 for men older than 39 years [64] in comparison to a younger age group.

A recently published study evaluating the influence of the paternal age on the aneuploidies rates in embryos obtained from donated oocytes found that men older than 50 years had higher aneuploidy rates in embryos compared to the groups of men younger than 39 years and between 40-49 years old [65]. 


\subsection{Abnormalities of the chromosomal structure}

Due to the continuous process of spermatogenesis during the lifetime of a man, the spermatogonia are prone to an increased risk of mutations through a high number of cell divisions. This process could be aggravated with increasing age due to the toxic effect of oxidative stress and decreased DNA repair capacity $[66,67]$. Moreover, increased paternal age is considered one of the major sources of mutations in humans [66].

\subsection{Telomere length}

Telomeres are regions of repetitive nucleotide sequences found at the end of the chromosomes, which have the function to protect the end of the chromosome from deterioration or from fusion with other chromosomes. Telomere length shortens with age and is associated with aging-related disorders. Telomere length decreases with every replication and, when a critical length is reached, cell division stops and cellular death appears. Although telomere shortening is considered to be related to advanced age and senescence [68], several studies reported a longer leucocytes telomere length in offspring of older fathers [69]. These findings are consistent with the longer telomere length reported in a subset of the sperm of older men. Probably this aspect is due to the selection of a particular germline stem cell subtype during the aging process with prolonged survival [69] but at the same time with affected mechanisms of healthy sperm selection [36].

The mechanisms connecting paternal age and telomere length of the offspring are not clearly elucidated. Although genome-wide association studies identified a number of genes linked to telomere length in general population, it is unlikely that increased number of mutations appearing with age in the paternal germline is the explanation for the observed association due to the rarity of these mutations [70].

One possible explanation is the age-dependent selection pressure in the male germline cells, older individuals having sperms with longer telomeres due to the selection process. This hypothesis is sustained by studies reporting a predominance of the sperm with longer telomers in older men [69].

Another hypothesis is offered by the different telomerase activities in somatic and germ-line cells. As such, telomerase is repressed in most somatic cells, whereas its activity is sustained in male germ-line stem cells [71]. Although the role of telomerase is to maintain the length of telomeres, after every replication of male germinal cells, a small increase with few base pairs seems to appear [72]. Due to the high number of replications of the germinal male cells over the life span, these small elongations accumulate, resulting in a significant increase of the telomere length in sperms of older men [70].

While most of the studies evaluated the relationship between paternal age and leucocytes telomere length, the positive correlation between paternal age and offspring sperm telomere length was for the first time reported in 2013 by a study evaluating a small sample ( 81 subjects) of young men (18-19 years old) [73]. However, in this study, the maternal age was also positively correlated to sperm telomere length, and the contribution of each parents' age was difficult to 
established due to the high correlation between parents age. They also found that sperm telomere length is related to sperm count, being lower in oligozoospermic than in normozoospermic men. These results confirmed the findings of Thilagavathi et al. [74] which reported shorter sperm telomere length in men with idiopathic infertility in comparison with controls [74]. Therefore, the number of studies linking infertility and low sperm count to shorter sperm telomere length is limited, and the question whether shorter sperm telomere length is the cause of infertility (through increased apoptosis of germ cells, impaired spermatogenesis, and reduced sperm count) or a marker of damaged spermatogenesis is yet to be answered by future studies.

Moreover, a study published in 2015 [75] reported a marked increase in sperm telomere length heterogeneity as men age and a longer length in samples with normal parameters in comparison with samples with abnormal parameters. These findings could have implications for infertile couples treated with assisted reproduction techniques due to a high probability of shorter telomere length in the offspring, taking into account the reported association between shorter telomere and depression, autism, neoplasia, and general poor health.

The exact implication of the paternal age at conception on the offspring health is not completely understood. Although it was generally considered to have a negative impact through the association with rare conditions like achondroplasia, Marfan syndrome, autism, and schizophrenia, it is also possible to be associated with a reduced risk of atherosclerosis and increased survival as longer telomere length confer this advantage [70].

Although telomere length is a complex genetic trait [76], several studies reported a possible impact of many other factors on telomere length like obesity, sleep disorders, smoking, and socio-economic factors, making the study the relationship between parental age and telomere length even more complicated.

\subsection{Epigenetics}

Data on the epigenetic changes related to paternal age are limited and refer mainly to modifications of methylation patterns observed in rats [77] and are considered to be involved in the appearance of Huntington disease, Alzheimer's disease, autism, or schizophrenia in humans [33].

\section{Aging and fertility in women}

Ovarian aging is a complex phenomenon that involves not only the reproductive function of the woman but also her global health status. Aging is characterized by a reduced number of oocytes and decreased fertility. Ovarian failure at menopause is associated with cardiovascular diseases, cognitive dysfunction, depression, and osteoporosis. The heat intolerance and hot flushes affect the quality of women life. Menopause is the final event in ovarian aging, with a mean age of occurrence of 51 years for the Caucasian population, with a range of individual variations due to genetic and environmental factors. Menopause is preceded by pre-menopause, a period that can last up to 10 years, characterized by a marked decline in fertility. The human follicles dynamic undergoes tremendous changes during this period, 
represented by a high rate of follicular atresia and a low rate of follicular growth, followed by exhaustion of follicular reserve, and, finally, occurrence of menopause.

The status of the women nowadays is changing, moving from high mortality and high fecundity to low mortality and low fecundity. There are remarkable changes in the dynamic of the world population and in the age distribution. It is estimated that in 2025 , the number of women over 60 years old will equal the number of women 15-24 years, reversing the actual status [78]. Moreover, there is a continuous increase in the number of employed women which, in association with the increase in educational demands of women, will contribute to the postponed age of maternity. Therefore, current trends of the society determine an increased number of women to try to conceive at an older age. This decision generates a serious health problem due to the decreased fertility and a high rate of pregnancy complications associated with advanced age. The statistics show that the fertility is decreased by $31 \%$ in women, 35-39 years old, in comparison with women who are 20-24 years, and the same decrease in fertility is mirrored by the success in assisted reproductive techniques [79].

The epidemiological studies reflect these societal changes, reporting an increase in the age of women at first birth from 22.7 in 1980 to 28.2 years in 2003 [80]. This change in the maternal age at first birth is relevant, taking into account that women over 30 years old who had not yet conceived had lower chances to obtain pregnancy than women who previously conceived at younger ages [80].

Ovarian aging implies qualitative and quantitative alteration of ovarian reserve and a consecutive decline in fertility. In women, the ovarian pool, which is formed during intrauterine life, is gradually depleted and the number of oocyte aneuploidies are gradually increasing with age. Therefore, the number of miscarriages and implantation failure are rising with age. The ovarian pool gradually declines, but there are some crucial steps at 34, 37, and 40 years when the decline accelerates. This ovarian pool is not subsequently renewed [81].

The age-related decline in follicle number is bi-exponential but doubles beyond a critical point at the age of 37.5 , when the number of follicles became less than $25,000[82,83]$. From this point till menopause, the time interval is around 13 years, this time period being characterized by a decline in fertility (a subfertility status). If we consider women who enter menopause at 45 years, the cut-off value of less than 25,000 follicles will be reached at the age of 32 . From a statistical point of view, $10 \%$ of women will enter menopause at 45 years, so there is $10 \%$ of women in the population who could potentially present subfertility since 32 years[84].

During intrauterine life, the ovary comprises 6 millions of oocytes surrounded by granulosa somatic cells, but because of atresia, only 1 million of primordial follicles remain at birth. At menarche, only 3,00,000 oocytes are left. During the female lifespan, approximately 400-500 follicles will ovulate [85].

Assisted reproduction technology had poor results in cases of ovarian aging, raising the economical, medical, and social cost of the procedures. On the other hand, oocyte donation programs have difficulties in finding donors. Social freezing of the oocytes creates various financial and storage problems and involves ethical issues and unequal access to medical care. 
Ovarian aging is a complex process that implies genetic modifications and metabolic changes, causing a decreased competence of the oocytes to become a viable embryo that could implant and ovulate. Aging is associated with chromosomal aberrations of the oocytes, an increase in ovarian DNA fragmentation, a shortening of the ovarian telomere length, a decreased mitochondrial function, dysfunction of the granulosa cells, and a decreased testosterone production by the ovary. The use of Fourier transform infrared spectroscopy (FTIR) showed meaningful macromolecular and biochemical changes in human ovaries. The decline in ovarian quality with age was associated with important modifications on composition and distribution of all principal biomolecules: proteins, lipids, carbohydrates, and nucleic acids.

During the developmental stages of folliculogenesis, the oocyte growth is accompanied by the proliferation and differentiation of the granulosa cells. At the antral stage, the granulosa cells differentiate in two very different phenotypically populations: the cumulus granulosa cells (CGCs) and the mural granulosa cells. The CGCs are involved in oocyte growth and maturation and the mural granulosa cells are responsible for steroidogenesis [86, 87]. There are gap junctions between the CGCs and the oocyte. The accumulation of damages in granulosa cells during the long quiescent phase before entering the growing phase, or the alteration of crosstalk between granulosa cells and oocyte, contributes to the impact of aging on oocyte [87].

Both the oocytes and primordial follicles could stay in the ovary till the fifth decade and then start to grow and form mature oocytes. $60 \%$ of women over 40 remain infertile, comparable with $6 \%$ at the age group 20-24 [88]. The chance of pregnancy in a cycle is $30 \%$ for women between 27-29 years and 15\% for women between 37-39 years. Natural delivery can occur after 45 years also but represents only $0.2 \%$ of total deliveries. However, most of the women that conceive at this age are multiparous [89]. It seems that the highest quality oocytes are used in the early reproductive years, leaving the less-competent oocytes for the fifth decade [90]. The chromosomal aberrations in the older ovaries are responsible for the increased number of embryo aneuploidies and miscarriages.

Kalmbach et al. [91] proposed the telomere shortening in the female germline as a central mechanism of reproductive aging in women [91]. The arguments for their theory are the studies on mice that demonstrated an association of telomere shortening with increases embryo fragmentation, cell cycle arrest, apoptosis, and chromosome abnormalities [92, 93]. In humans, it was reported that shorter telomeres in the oocytes of women undergoing in vitro fertilization were linked to the presence of fragmented, aneuploid embryos that fail to implant [94].

Mitochondria represent the powerhouse of the cells, producing the energy necessary for cellular functions. The ATP required for cellular energetic needs is produced by mitochondrial oxidative phosphorylation (OXPHOS). A toxic product of OXPHOS is endogenous reactive oxygen species (ROS). Natural defense mechanisms protect the cells against the damages produced by ROS, but if these mechanisms are decreased, the cells could be damaged. In the ovary, ROS may be involved in the regulation of follicular development or apoptosis through the modulation of ROS scavenging systems [95].

The theory of the free radicals' role in ovarian aging, which is 50 years old, says that these free radicals progressively accumulate with age and determine damages of the ovarian 
compartments and the decrease in ovarian function [96]. The evidences for this old theory are provided by studies showing a significant increase in oxidatively damaged lipids, proteins, and DNA [97] and a decrease in antioxidant defense in aging ovary [98, 99].

The increase of oxidative stress with ovarian aging could contribute to follicular atresia and a poor quality of oocytes as well [98]. Moreover, oxidative stress damages the telomeres and accelerates their shortening.

Mitochondria have their own genome in the form of mtDNA. This DNA is unstable in aging ovary. The maternal transmission of mtDNA is well established, and paternal transmission of mtDNA is being seen only in some pathological cases. Oocytes have a well-defined role in eliminating paternal mtDNA, but this ability has decreased in poor quality oocytes. The close relationship observed between mitochondrial dysfunctions and poor reproductive performance, which could be solved by injection of healthy mitochondria from another woman, led to the concept that the age of the ovary is related to the age of the mitochondrial function. Other signs of ovarian aging are point mutations or deletions of mitochondrial DNA.

Another theory is referring to the carbonyl stress in the aging follicle. Reactive carbonyl species (RCS) are reactive endogenous metabolites derived from metabolic processes. Unlike ROS, the damages produced by the RCS to the cells are more severe due to the increased stability of these products and their ability to attach to targets far from the site of their formation [100]. RCS determine post-translational modifications which finally form advanced glycation end-products (AGEs). Between AGEs and oxidative stress, there is a complex interplay with oxidative stress contributing to AGEs production [101].

These products accumulate in the ovary and promote the wide spatiotemporal spread of oxidative stress. These modifications affect the ovarian microenvironment during folliculogenesis, influencing the developmental capacity of the oocytes. It was also suggested that AGEs produce perturbation in perifollicular vascularization by a complex relationship with vascular endothelial growth factor (VEGF) [102, 103]. Therefore, the maturation, chromosomal constitution of the oocytes, and granulosa cell metabolism are modified. The granulosa cells are affected by oxidative stress including the glycosylation end products, resulting in a decrease in proliferation and an increase in apoptosis of the cells. Proteins modified by AGEs interact with specific receptors (RAGE) and through them determine the activation of the cell's response. The soluble RAGE could be measured in the follicular fluid and in the serum, and this is the method for quantifying the role of AGEs in ovarian aging and ovarian dysfunction. The study of Sato et al. [104] demonstrated that toxic AGE level in follicular fluid and in serum is negatively correlated with follicular growth, fertilization, and embryonic development [104].

One of the first endocrinological markers of ovarian aging is the early rise in day 3 folliclestimulating hormone (FSH), together with the early elevation in estradiol levels and a more rapid growth of the follicles. First, there is a shortening of the follicular phase of the ovary and, later in the aging process, it is affected by the length of luteal phase and the value of serum luteal progesterone. Higher day 3 FSH level generally correlates with lower ovarian reserve and lower chances for pregnancy, the exception being FSH receptor variant. The cutoff value for subfertile population is generally considered a serum FSH of $12.3 \mathrm{UI} / \mathrm{l}$. Other two 
markers of ovarian aging are antimullerian hormone (AMH) and antral follicle counts (AFC). AFC could be visualized by transvaginal ultrasonography, but the way AFC is performed differs between the centers. There are centers measuring follicles between 2-10 $\mathrm{mm}$ and others measuring follicles between 2-6 mm. It seems that smaller follicles, less than $6 \mathrm{~mm}$, correlate better with ovarian reserve. In ART (assisted reproductive technology) literature, a lower AFC is associated with poor response to ovarian stimulation, although variable cut-offs were used, usually less than six. It was suggested that AFC is a better marker of ovarian reserve than $\mathrm{AMH}$ due to the factors potentially influencing circulating level of $\mathrm{AMH}$ (for instance, obesity). For AMH, the cut-off value for subfertility is considered $1 \mathrm{ug} / \mathrm{l}$ (Singer). It was also suggested that the response to ovarian stimulation during ART is a predictor of menopause based on the observation that women with a poor response experience early menopause and show menstrual cycle characteristics seen in ovarian aging. For the evaluation of the fertility potential of the women, it is important not only the age but also the number of years that elapse till menopause. At this moment, there is no gold standard for evaluating functional ovarian age. It seems that FSH-stimulated serum inhibin B level correlates best with ovarian age [105]. This stimulated serum inhibin B level reflects the pool of immature follicles, those not visible by ultrasound and not capable of estradiol production. With age the pool of immature follicles decreases accompanied by a decrease of serum level of inhibin B.

Very interestingly, in women with polycystic ovary syndrome (PCOS) with aging, the regular cycles are more regular, serum androgen levels decrease, and insulin resistance is ameliorated. In this case, the diminished pool of growing antral follicles determines a decrease in the AMH level. Women with PCOS have a large initial pool of follicles, having a low risk for early ovarian aging.

A particular case of ovarian aging is represented by women with premature ovarian failure (POF), representing 20\% of infertile population. These patients associate with an increased risk of miscarriages [106] and a poor response to ovarian stimulation. POF refers to women with ovarian insufficiency before the age of 40 . The genetic and autoimmune factors are the most important causes of POF. POF could appear also iatrogenic after surgery or chemotherapy [107].

Ovarian aging is accompanied by endometrial aging. The old endometrium is still responsive to ovarian steroids and is characterized by increase in collagen content, a reduced number of stromal cells, reduced tissue deoxyribonucleic acid contents, and fewer estrogen receptors on endometrial cells. There is significant evidence that aging endometrium is a major determinant of reduced fecundity, where age and aging ovaries are the major determinant of higher abortion rate with age. In women older than 35 years, endometrial biopsy shows delayed or absent secretory maturation which determines implantation failure. However, IVF donor programs show satisfactory pregnancy rates in older women; therefore, from the reproductive point of view, the aging ovary is more important than the aging endometrium.

\section{Conclusions}

The inexorable effect of age on ovarian function is well known with a gradual decline in fertility by the age of 40 , followed by an abrupt decrease thereafter and a cessation of ovarian 
function at menopause. The impact of age is not only due to a decreased number but also due to a decrease in quality of the oocytes, resulting in a high rate of chromosomal aneuploidy and a reduced implantation rate. The main mechanism assumed to be involved in ovarian aging is a reduced defense against oxidative stress, ROS, and RCS accumulation which damage the ovarian compartments, generating shortening of the telomeres and mitochondrial dysfunction.

On the other hand, in men, the semen quality and testicular function were found to gradually decrease with age, and most of the studies also describe a negative impact on fertility. The mechanisms underlying decreased fertility are genetic (chromosomal aneuploidies, DNA mutations) and epigenetics changes. However, whether these effects of aging in men can be overcome by assisted reproductive technologies is not clear yet as the results of the studies are inconsistent.

\section{Author details}

Alice Ioana Albu* and Dragos Albu

*Address all correspondence to: albualice@yahoo.com

Carol Davila University of Medicine and Pharmacy, Bucharest, Romania

\section{References}

[1] Bray I, Gunnell D, Davey SG. Advanced paternal age: How old is too old? Journal of Epidemiology and Community Health. 2006;60:851-853

[2] Office for National Statistics. Birth Statistics: Review of the Registrar General on Births and Family Building Patterns in England and Wales. London: Stationery Office; 2002

[3] Olsen J. Subfecundity according to the age of the mother and the father. Danish Medical Bulletin. 1990;37:281-282

[4] Joffe M, Li Z. Male and female factors in fertility. American Journal of Epidemiology. 1994;140(10):921-929

[5] Sallmen M, Luukkonen R. Is the observed association between increasing paternal age and delayed conception an artefact? Human Reproduction. 2001;16:2027-2028

[6] de La Rochebrochard E, Thonneau P. Paternal age or 1/440 years: An important risk factor for infertility. American Journal of Obstetrics and Gynecology. 2003;189:901-905

[7] Hassan MA, Killick SR. Effect of male age on fertility: Evidence for the decline in male fertility with increasing age. Fertility and Sterility. 2003;79:1520-1527

[8] Araujo AB, Mohr BA, McKinlay JB. Changes in sexual function in middle-aged and older men: Longitudinal data from the Massachusetts Male Aging Study. Journal of the American Geriatrics Society. 2004;52:1502-1509 
[9] Dunson DB, Baird DD, Colombo B. Increased infertility with age in men and women. Obstetrics \& Gynecology. 2004;103:51-56

[10] Wu FCW, Tajar A, Pye SR, Silman AJ, Finn JD, O’Neill TW, Bartfai G, Casanueva F, Forti G, Giwercman A, et al. Hypothalamic-pituitary-testicular axis disruptions in older men are differentially linked to age and modifiable risk factors: The European Male Aging Study. Journal of Clinical Endocrinology and Metabolism. 2008;93:2737-2745

[11] Kaufman JM, Vermeulen A. The decline of androgen levels in elderly men and its clinical and therapeutic implications. Endocrine Reviews. 2005;26:833-876

[12] Harman SM, Metter EJ, Tobin JD, Pearson J, Blackman MR. Longitudinal effects of aging on serum total and free testosterone levels in healthy men. Journal of Clinical Endocrinology and Metabolism. 2001;86:724-731

[13] Feldman HA, Longcope C, Derby CA, Johannes CB, Araujo AB, Coviello AD, Bremner WJ, McKinlay JB. Age trends in the level of serum testosterone and other hormones in middle-aged men: Longitudinal results from the Massachusetts Male Aging Study. Journal of Clinical Endocrinology and Metabolism. 2002;87:589-598

[14] Derby CA, Zilber S, Brambilla D, Morales KH, McKinlay JB. Body mass index, waist circumference and waist to hip ratio and change in sex steroid hormones: The Massachusetts Male Ageing Study. Clinical Endocrinology. 2006;65:125-131

[15] Mohr BA, Bhasin S, Link CL, O'Donnell AB, McKinlay JB. The effect of changes in adiposity on testosterone levels in older men: Longitudinal results from the Massachusetts Male Aging Study. European Journal of Endocrinology. 2006;155:443-452

[16] Travison TG, Araujo AB, Kupelian V, O'Donnell AB, McKinlay JB. The relative contributions of aging, health, and lifestyle factors to serum testosterone decline in men. Journal of Clinical Endocrinology and Metabolism. 2007;92:549-555

[17] Lapauw B, Goemaere S, Zmierczak H, Van Pottelbergh I, Mahmoud A, Taes Y, De Bacquer D, Vansteelandt S, Kaufman JM. The decline of serum testosterone levels in community-dwelling men over 70 years of age: Descriptive data and predictors of longitudinal changes. European Journal of Endocrinology. 2008;159:459-468

[18] Camacho EM, Huhtaniemi IT, O'Neill TW, Finn JD, Pye SR, Lee DM, Tajar A, Bartfai G, Boonen S, Casanueva FF, Forti G, Giwercman A, Han TS, Kula K, Keevil B, Lean ME, Pendleton N, Punab M, Vanderschueren D, Wu FC, The EMAS Group. Age-associated changes in hypothalamic-pituitary-testicular function in middle-aged and older men are modified by weight change and lifestyle factors: Longitudinal results from the European Male Ageing Study. European Journal of Endocrinology. 2013;168:445-455

[19] Wu FC, Tajar A, Beynon JM, et al. Identification of late-onset hypogonadism in middleaged and elderly men. New England Journal of Medicine. 2010;363:123-135

[20] Neaves WB, Johnson L, Porter JC, Parker Jr CR, Petty CS. Leydig cell numbers, daily sperm production, and serum gonadotropin levels in aging men. Journal of Clinical Endocrinology and Metabolism. 1984;59:756-763 
[21] Veldhuis JD, Veldhuis NJ, Keenan DM, Iranmanesh A. Age diminishes the testicular steroidogenic response to repeated intravenous pulses of recombinant human LH during acute GnRH-receptor blockade in healthy men. American Journal of Physiology Endocrinology and Metabolism. 2005 Apr;288(4):E775-E781. [Epub: November 30, 2004]

[22] Winters SJ, Wang C, Fortigel Study Group. LH and non-SHBG testosterone and estradiol levels during testosterone replacement of hypogonadal men: Further evidence that steroid negative feedback increases as men grow older. Journal of Andrology. 2010 MayJun;31(3):281-287. DOI: 10.2164/jandrol.109.009035. [Epub: December 3, 2009]

[23] Huhtaniemi IT, Pye SR, Holliday KL, Thomson W, O’Neill TW, Platt H, Payne D, John SL, Jiang M, Bartfai G, Boonen S, Casanueva FF, Finn JD, Forti G, Giwercman A, Han TS, Kula K, Lean ME, Pendleton N, Punab M, Silman AJ, Vanderschueren D, Labrie F, Wu FC, European Male Aging Study Group. Effect of polymorphisms in selected genes involved in pituitary-testicular function on reproductive hormones and phenotype in aging men. Journal of Clinical Endocrinology and Metabolism. 2010 Apr;95(4):18981908. DOI: 10.1210/jc.2009-2071. [Epub: February 19, 2010]

[24] Rolf C, Behre HM, Nieschlag E. Reproductive parameters of older compared to younger men of infertile couples. International Journal of Andrology. 1996 Jun;19(3):135-142

[25] Andolz P, Bielsa MA, Vila J. Evolution of semen quality in North-Eastern Spain: A study in 22,759 infertile men over a 36 year period. Human Reproduction. 1999 Mar;14(3):731-735

[26] Auger J, Kunstmann JM, Czyglik F, Jouannet P. Decline in semen quality among fertile men in Paris during the past 20 years. New England Journal of Medicine. 1995 Feb 2;332(5):281-285

[27] Schwartz D, Mayaux MJ, Spria A, Moscato ML, Jouannet P, Czyglik F, David G. Semen characteristics as a function of age in 833 fertile men. Fertility and Sterility. 1983;39:530-535

[28] Fisch H, Goluboff ET, Olson JH, Feldshuh J, Broder SJ, Barad DH. Semen analysis in 1,283 men from the United States over a 25-year period: No decline in quality. Fertility and Sterility. 1996;65:1009-1014

[29] Rolf C, Kenkel S, Nieschlag E. Age-related disease pattern in infertile men: Increasing incidence of infections in older patients. Andrologia. 2002;34:209-217. DOI: 10.1046/j.1439-0272.2002. 00505.x

[30] Brahem S, Mehdi M, Elghezal H, Saad A. The effects of male aging on semen quality, sperm DNA fragmentation and chromosomal abnormalities in an infertile population. Journal of Assisted Reproduction and Genetics. 2011 May;28(5):425-432. DOI: 10.1007/ s10815-011-9537-5. [Epub: February 3, 2011]

[31] Petersen PM, Seierøe K, Pakkenberg B. The total number of Leydig and Sertoli cells in the testes of men across various age groups - a stereological study. Journal of Anatomy. 2015 Feb;226(2):175-179. DOI: 10.1111/joa.12261. [Epub: December 25, 2014]

[32] Jiang H, Zhu WJ, Li J, Chen QJ, Liang WB, Gu YQ. Quantitative histological analysis and ultrastructure of the aging human testis. International Urology and Nephrology. 2014 May;46(5):879-885. DOI: 10.1007/s11255-013-0610-0. [Epub: November 26, 2013] 
[33] Sartorius GA, Nieschlag E. Paternal age and reproduction. Human Reproduction. 2010;16(1):65-79

[34] Johnson SL, Dunleavy J, Gemmell NJ, Nakagawa S. Consistent age-dependent declines in human semen quality: A systematic review and meta-analysis. Ageing Research Reviews. 2015;19:22-33

[35] Moskovtsev SI, Willis J, Mullen JB. Age-related decline in sperm deoxyribonucleic acid integrity in patients evaluated for male infertility. Fertility and Sterility. 2006;85:496-499

[36] Singh NP, Muller CH, Berger RE. Effects of age on DNA double-strand breaks and apoptosis in human sperm. Fertility and Sterility. 2003;80:1420-1430

[37] Spano M, Bonde JP, Hjollund HI, Kolstad HA, Cordelli E, Leter G. Sperm chromatin damage impairs human fertility. The Danish First Pregnancy Planner Study Team. Fertility and Sterility. 2000;73:43-50

[38] Giwercman A, Lindstedt L, Larsson M, Bungum M, Spano M, Levine RJ, et al. Sperm chromatin structure assay as an independent predictor of fertility in vivo: A case-control study. International Journal of Andrology. 2010;33:e221-e227

[39] Loft S, Kold-Jensen T, Hjollund NH, Giwercman A, Gyllemborg J, Ernst E, et al. Oxidative DNA damage in human sperm influences time to pregnancy. Human Reproduction. 2003;18:1265-1272

[40] Zini A. Are sperm chromatin and DNA defects relevant in the clinic? Systems Biology in Reproductive Medicine. 2011;57:78-85

[41] Bungum M, Humaidan P, Axmon A, Spano M, Bungum L, Erenpreiss J, et al. Sperm DNA integrity assessment in prediction of assisted reproduction technology outcome. Human Reproduction. 2007;22:174-179

[42] Collins JA, Barnhart KT, Schlegel PN. Do sperm DNA integrity tests predict pregnancy with in vitro fertilization? Fertility and Sterility. 2008;89:823-831

[43] Practice Committee of the American Society for Reproductive Medicine. The clinical utility of sperm DNA integrity testing: A guideline. Fertility and Sterility. 2013;99:673-677

[44] Robinson L, Gallos ID, Conner SJ, Rajkhowa M, Miller D, Lewis S, et al. The effect of sperm DNA fragmentation on miscarriage rates: A systematic review and meta-analysis. Human Reproduction. 2012;27:2908-2917

[45] Frattarelli JL, Miller KA, Miller BT, Elkind-Hirsch K, Scott Jr RT. Male age negatively impacts embryo development and reproductive outcome in donor oocyte assisted reproductive technology cycles. Fertility and Sterility. 2008;90:97-103

[46] Wdowiak A, Bakalczuk S, Bakalczuk G. The effect of sperm DNA fragmentation on the dynamics of the embryonic development in intracytoplasmatic sperm injection. Reproductive Biology. 2015 Jun;15(2):94-100. DOI: 10.1016/j.repbio.2015.03.003. [Epub: April 2, 2015] 
[47] Simon L, Murphy K, Shamsi MB, Liu L, Emery B, Aston KI. Paternal influence of sperm DNA integrity on early embryonic development. Human Reproduction. 2014;29:2402-2412

[48] Borini A, Tarozzi N, Bizzaro D, Bonu MA, Fava L, Flamigni C, Coticchio G. Sperm DNA fragmentation: Paternal effect on early post-implantation embryo development in ART. Human Reproduction. 2006 Nov;21(11):2876-2881. [Epub: June 22, 2006]

[49] Sivanarayana T, Krishna ChR, Prakash GJ, Krishna KM, Madan K, Rani BS, Sudhakar G, Raju GA. CASA derived human sperm abnormalities: Correlation with chromatin packing and DNA fragmentation. Journal of Assisted Reproduction and Genetics. 2012 Dec;29(12):1327-1334. DOI: 10.1007/s10815-012-9885-9. [Epub: November 8, 2012]

[50] Martin RH. Meiotic errors in human oogenesis and spermatogenesis. Reproductive BioMedicine Online. 2008 Apr;16(4):523-531

[51] Griffin DK, Abruzzo MA, Millie EA, Sheean LA, Feingold E, Sherman SL, Hassold TJ. Non-disjunction in human sperm: Evidence for an effect of increasing paternal age. Human Molecular Genetics. 1995;4:2227-2232

[52] Sharma R, Agarwal A, Rohra VK, Assidi M, Abu-Elmagd M, Turki RF. Effects of increased paternal age on sperm quality, reproductive outcome and associated epigenetic risks to offspring. Reproductive Biology and Endocrinology. 2015;13:35. DOI: 10.1186/s12958-015-0028-x

[53] Bosch M, Rajmil O, Egozcue J, Templado C. Linear increase of structural and numerical chromosome 9 abnormalities in human sperm regarding age. European Journal of Human Genetics. 2003 Oct;11(10):754-759

[54] Fonseka KG, Griffin DK. Is there a paternal age effect for aneuploidy? Cytogenetic and Genome Research. 2011;133(2-4):280-291. DOI: 10.1159/000322816. [Epub: January 6, 2011]

[55] Dakouane-Giudicelli M, Bicchieray L, Bergere M, Albert M, Vialard F, Selva J. A histomorphometric and cytogenetic study of testis from men 29-102 years old. Fertility and Sterility. 2005 Apr;83(4):923-928

[56] Brinkworth $\mathrm{MH}$, Schmid TE. Effect of age on testicular germ cell apoptosis and sperm aneuploidy in MF-1 mice. Teratogenesis, Carcinogenesis, and Mutagenesis. 2003;(Suppl 2): 103-109

[57] De Souza E, Morris JK, EUROCAT Working Group. Collaborators. Case-control analysis of paternal age and trisomic anomalies. Archives of Disease in Childhood. 2010 Nov;95(11):893-897. DOI: 10.1136/adc.2009.176438. [Epub: June 28, 2010]

[58] Arnedo N, Templado C, Sánchez-Blanque Y, Rajmil O, Nogués C. Sperm aneuploidy in fathers of Klinefelter's syndrome offspring assessed by multicolour fluorescent in situ hybridization using probes for chromosomes 6, 13, 18, 21, 22, X and Y. Human Reproduction. 2006 Feb;21(2):524-528. [Epub: September 30, 2005] 
[59] Steiner B, Masood R, Rufibach K, Niedrist D, Kundert O, Riegel M, Schinzel A. An unexpected finding: Younger fathers have a higher risk for offspring with chromosomal aneuploidies. European Journal of Human Genetics. 2015 Apr;23(4):466-472. DOI: 10.1038/ ejhg.2014.122. [Epub: July 9, 2014]

[60] Fisch H, Hyun G, Golden R, Hensle TW, Olsson CA, Liberson GL. The influence of paternal age on Down syndrome. Journal of Urology. 2003;169:2275-2278

[61] Hassold T, Sherman S. Down syndrome: Genetic recombination and the origin of the extra chromosome 21. Clinical Genetics. 2000;57:95-100

[62] Hatch M, Kline J, Levin B, Hutzler M, Warburton D. Paternal age and trisomy among spontaneous abortions. Human Genetics. 1990;85:355-361

[63] Naguib KK, Al-Awadi SA, Moussa MA, Bastaki L, Gouda S, Redha MA, Mustafa F, Tayel SM, Abulhassan SA, Murthy DS. Trisomy 18 in Kuwait. International Journal of Epidemiology. 1999;28:711-716

[64] Archer NP, Langlois PH, Suarez L, Brender J, Shanmugam R. Association of paternal age with prevalence of selected birth defects. Birth Defects Research Part A: Clinical and Molecular Teratology. 2007;79:27-34

[65] García-Ferreyra J, Luna D, Villegas L, Romero R, Zavala P, Hilario R, Dueñas-Chacón J. High aneuploidy rates observed in embryos derived from donated oocytes are related to male aging and high percentages of sperm DNA fragmentation. Clinical Medicine Insights: Reproductive Health. 2015 Nov 11;9:21-27. DOI: 10.4137/CMRH.S32769. [eCollection 2015]

[66] Crow JF. The origins, patterns and implications of human spontaneous mutation. Nature Reviews Genetics. 2000;1:40-47

[67] Kong A, Frigge ML, Masson G, Besenbacher S, Sulem P, Magnusson G, et al. Rate of de novo mutations and the importance of father's age to disease risk. Nature. 2012;488: $471-475$

[68] Martien S, Abbadie C. Acquisition of oxidative DNA damage during senescence: The first step toward carcinogenesis? Annals of the New York Academy of Sciences. 2007;1119:51-63

[69] Kimura M, Cherkas LF, Kato BS, Demissie S, Hjelmborg JB, Brimacombe M, Cupples A, Hunkin JL, Gardner JP, Lu X, Cao X, Sastrasinh M, Province MA, Hunt SC, Christensen K, Levy D, Spector TD, Aviv A. Offspring's leukocyte telomere length, paternal age, and telomere elongation in sperm. PLoS Genetics. 2008 Feb;4(2):e37. DOI: 10.1371/journal. pgen.0040037

[70] Aviv A, Susser E. Leukocyte telomere length and the father's age enigma: Implications for population health and for life course. International Journal of Epidemiology. 2013 Apr;42(2):457-462. DOI: 10.1093/ije/dys236. [Published online: February 4, 2013]

[71] Wright WE, Piatyszek MA, Rainey WE, Byrd W, Shay JW. Telomerase activity in human germline and embryonic tissues and cells. Developmental Genetics. 1996;18(2):173-179 
[72] Aston KI, Hunt SC, Susser E, et al. Divergence of sperm and leukocyte age-dependent telomere dynamics: Implications for male-driven evolution of telomere length in humans. Molecular Human Reproduction. 2012;18:517-522

[73] Ferlin A, Rampazzo E, Rocca MS, Keppel S, Frigo AC, De Rossi A, Foresta C. In young men sperm telomere length is related to sperm number and parental age. Human Reproduction. 2013 Dec;28(12):3370-3376. DOI: 10.1093/humrep/det392. [Epub: October $27,2013]$

[74] Thilagavathi J, Venkatesh S, Dada R. Telomeres length in reproduction. Andrologia. 2013 Oct;45(5):289-304

[75] Antunes DM, Kalmbach KH, Wang F, Dracxler RC, Seth-Smith ML, Kramer Y, BuldoLicciardi J, Kohlrausch FB, Keefe DL. A single-cell assay for telomere DNA content shows increasing telomere length heterogeneity, as well as increasing mean telomere length in human spermatozoa with advancing age. Journal of Assisted Reproduction and Genetics. 2015 Nov;32(11):1685-1690. DOI: 10.1007/s10815-015-0574-3. [Epub: September 28, 2015]

[76] Allsopp RC, Vaziri H, Patterson C, Goldstein S, Younglai EV, Futcher AB, Greider CW, Harley CB. Telomere length predicts replicative capacity of human fibroblasts. Proceedings of the National Academy of Sciences of the United States of America. 1992;89:10114-10118

[77] Oakes CC, Smiraglia DJ, Plass C, Trasler JM, Robaire B. Aging results in hypermethylation of ribosomal DNA in sperm and liver of male rats. Proceedings of the National Academy of Sciences of the United States of America. 2003;100:1775-1780

[78] Bloom DE. 7 billion and counting. Science. 2011;333:562-569

[79] Menken J, Trussell J, Larsen U. Age and infertility. Science. 1986;233:1389-1394

[80] Gray RH, Wu LY. Subfertility and risk of spontaneous abortion. American Journal of Public Health. 2000;90:1432-1434

[81] Gleicher N. Ovarian aging: Is there a "norm"? Contemporary Obstetrics and Gynaecology. 2005;50:65-75

[82] Faddy MJ, Gosden RG. A model conforming the decline in follicle numbers to the age of menopause in women. Human Reproduction. 1996;11:1484-1486

[83] Faddy MJ, Gosden RG. A mathematical model of follicle dynamics in the human ovary. Human Reproduction. 1995;10:770-775

[84] Gleicher N, Weghofer A, Barad D. Female infertility due to abnormal autoimmunity: Frequently overlooked and greatly underappreciated. Part I. Expert Review of Obstetrics \& Gynecology. 2007;2:453-464

[85] Gleicher N, Weghofer A, Barad D. Female infertility due to abnormal autoimmunity: Frequently overlooked and greatly underappreciated. Part II. Expert Review of Obstetrics \& Gynecology. 2007;2:465-475 
[86] Feuerstein P, Puard V, Chevalier C, Teusan R, Cadoret V, Guerif F, et al. Genomic assessment of human cumulus cell marker genes as predictors of oocyte developmental competence: Impact of various experimental factors. PLoS One. 2012;7:e40449

[87] Tatone C, Amicarelli F. The aging ovary - the poor granulosa cells. Fertility and Sterility. 2013;99:12-17

[88] Hardy R, Kuh D. Reproductive characteristics and the age at inception of the perimenopause in a British National Cohort. American Journal of Epidemiology. 1999;149:612-620

[89] Faddy MJ. Follicle dynamics during ovarian aging. Molecular and Cellular Endocrinology. 2000 May;163(1-2):43-48

[90] Gleicher N, Barad DH. The aging ovary. In: Deligdisch L, Kase NG, Cohen CJ, eds. Altchek's Diagnosis and Management of Ovarian Disorders. 3rd ed. Cambridge: Cambridge University Press; 2013:275-286. DOI:10.1017/CBO9781139003254.020

[91] Kalmbach KH, Fontes Antunes DM, Dracxler RC, Knier TW, Seth-Smith ML, Wang F, Liu L, Keefe DL. Telomeres and human reproduction. Fertility and Sterility. 2013 Jan;99(1):23-29. DOI: 10.1016/j.fertnstert.2012.11.039

[92] Liu L, Franco S, Spyropoulos B, Moens PB, Blasco MA, Keefe DL. Irregular telomeres impair meiotic synapsis and recombination in mice. Proceedings of the National Academy of Sciences of the United States of America. 2004 Apr 27;101(17):6496-6501

[93] Liu L, Blasco MA, Keefe DL. Requirement of functional telomeres for metaphase chromosome alignments and integrity of meiotic spindles. EMBO Reports. 2002 Mar;3(3):230-234

[94] Keefe DL, Liu L, Marquard K. Telomeres and aging-related meiotic dysfunction in women. Cellular and Molecular Life Sciences. 2007 Jan;64(2):139-143

[95] Agarwal A, Aponte-Mellado A, Premkumar BJ, Shaman A, Gupta S. The effects of oxidative stress on female reproduction: A review. Reproductive Biology and Endocrinology. 2012;10:49

[96] Harman D. Aging: A theory based on free radical and radiation chemistry. Journal of Gerontology. 1956;11:298-300

[97] Lim J, Luderer U. Oxidative damage increases and antioxidant gene expression decreases with aging in the mouse ovary. Biology of Reproduction. 2011;84:775-782

[98] Ito M, Muraki M, Takahashi Y, Imai M, Tsukui T, Yamakawa N, et al. Glutathione S-transferase theta 1 expressed in granulosa cells as a biomarker for oocyte quality in age-related infertility. Fertility and Sterility. 2008;90:1026-1035

[99] Ito M, Imai M, Muraki M, Miyado K, Qin J, Kyuwa S, et al. GSTT1 is upregulated by oxidative stress through p38-MK2 signaling pathway in human granulosa cells: Possible association with mitochondrial activity. Aging. 2011;3:1213-1223

[100] Mano J. Reactive carbonyl species: Their production from lipid peroxides, action in environmental stress, and the detoxification mechanism. Plant Physiology and Biochemistry. 2012;59: 90-97 
[101] Goldin A, Beckman JA, Schmidt AM, Creager MA. Advanced glycation end products: Sparking the development of diabetic vascular injury. Circulation. 2006;114:597-605

[102] Fujii EY, Nakayama M. The measurements of RAGE, VEGF, and AGEs in the plasma and follicular fluid of reproductive women: The influence of aging. Fertility and Sterility. 2010;94:694-700

[103] Yeh J, Kim BS, Peresie J. Ovarian vascular endothelial growth factor and vascular endothelial growth factor receptor patterns in reproductive aging. Fertility and Sterility. 2008;89:1546-1556

[104] Sato T, Iwaki M, Shimogaito N, Wu X, Yamagishi S, Takeuchi M. TAGE (toxic AGEs) theory in diabetic complications. Current Molecular Medicine. 2006;6:351-358

[105] Gleicher N, Weghofer A, Oktay K, Barad D. Can the FMR1 (fragile X) gene serve as predictor of response to ovarian stimulation? Reproductive Sciences. 2008 Feb;16(5):462467. DOI: $10.1177 / 1933719108328617$

[106] Chand AL, Robertson DM, Shelling AN, Harrison CA. Mutational analysis of betaglycan/TGF-betaRill in premature ovarian failure. Fertility and Sterility. 2007;87:210-212

[107] Dixit H, Rao KL, Padmalatha VV, Kanakavalli M, Deenadayal M, Gupta N, Chakrabarty $\mathrm{BN}$, Singh L. Mutational analysis of the betaglycan gene-coding region in susceptibility for ovarian failure. Human Reproduction. 2006;21:2041-2046 